\title{
Does IBD Portend Worse Outcomes in Patients with Rectal Cancer? A Case-Matched Analysis
}

\author{
Ahmad Alsughayer, M.B.B.S. ${ }^{1}$ Fabian Grass, M.D. ${ }^{1}$ Nicholas P. McKenna, M.D. ${ }^{2}$ \\ Molly Petersen, B.S. ${ }^{3}$ Kellie L. Mathis, M.D., M.Sc. ${ }^{1}$ Amy L. Lightner, M.D. ${ }^{4}$ \\ 1 Division of Colon and Rectal Surgery, Mayo Clinic, Rochester, Minnesota \\ 2 Department of General Surgery, Mayo Clinic, Rochester, Minnesota \\ 3 Department of Biomedical Statistics and Informatics, Mayo Clinic, Rochester, Minnesota \\ 4 Department of Colorectal Surgery, Cleveland Clinic, Cleveland, Ohio
}

BACKGROUND: Patients with IBD are at increased risk for developing colorectal cancer. However, overall survival and disease-free survival for rectal cancer alone in patients with IBD has not been reported.

OBJECTIVE: This study aimed to determine overall survival and disease-free survival for patients with rectal cancer in IBD versus non-IBD cohorts.

DESIGN: This is a retrospective cohort study.

SETTING: This study was conducted at an IBD referral center.

PATIENTS: All consecutive adult patients with IBD diagnosed with rectal cancer and at least 1 year of postsurgery follow-up were included and matched in a 1:2 fashion (age, sex, preoperative stage) with patients with rectal cancer who did not have IBD.

MAIN OUTCOMES MEASURES: Five-year overall survival and disease-free survival, 30-day postoperative complication, readmission, reoperation, and mortality rates were measured.

METHODS: Survival rates were calculated using KaplanMeier estimates. The association of risk factors and longterm outcomes was assessed using Cox proportion hazard models.

Funding/Support: None reported.

Financial Disclosures: Amy Lightner - Consultant fees from Takeda.

Ahmad Alsughayer and Fabian Grass shared first authorship.

Correspondence: Amy L. Lightner, M.D., Digestive Disease Institute, Cleveland Clinic, 9500 Euclid Ave, Cleveland, OH 44195. E-mail: Lightna@ccf.org

Dis Colon Rectum 2020; 63: 1265-1275

DOI: $10.1097 /$ DCR.0000000000001666

(c) The ASCRS 2020
RESULTS: A total of 107 study patients with IBD who had rectal cancer were matched to 215 control patients; preoperative stages were as follows: $31 \%$ with stage I, $19 \%$ with stage II, $40 \%$ with stage III, and $10 \%$ with stage IV. Differences were observed (IBD vs non-IBD) in neoadjuvant chemotherapy ( $33.6 \%$ vs $52.6 \%, p=0.001$ ) and preoperative radiotherapy ( $35.5 \%$ vs $53.5 \%$, $p=0.003)$. Postoperative complication rates were similar. On surgical pathology, patients with IBD had more lymphovascular invasion $(12.9 \%$ vs $5.6 \%, p=0.04)$ and positive circumferential resection margins ( $5.4 \%$ vs $0.9 \%$, $p=0.03$ ). On multivariable analysis, the diagnosis of IBD did not significantly impact long-term mortality (HR, $0.91 ; 95 \%$ CI, $0.53-1.57 ; p=0.73$ ) or disease-free survival (HR, 1.36; 95\% CI, 0.84-2.21; $p=0.22$ ).

LIMITATIONS: This study was limited by its retrospective design and the use of single-center data.

CONCLUSIONS: Patients have rectal cancer with IBD and without IBD have similar long-term and disease-free survival, despite lower rates of neoadjuvant treatment and higher margin positivity in patients with IBD. See Video Abstract at http://links.lww.com/DCR/B271.

¿LA ENFERMEDAD INFLAMATORIA INTESTINAL ACARREA PEORES RESULTADOS EN PACIENTES CON CÁNCER RECTAL? UN ANÁLISIS DE CASOS-COINCIDENTES

ANTECEDENTES: Los pacientes con enfermedad inflamatoria intestinal (EII) tienen un mayor riesgo de desarrollar cáncer colorrectal. Sin embargo, no se ha informado la supervivencia general y la supervivencia libre de enfermedad para el cáncer rectal solo en pacientes con EII.

OBJETIVO: Determinar la supervivencia general y la supervivencia libre de enfermedad para pacientes con cáncer rectal en cohortes con EII versus sin EII.

DISEÑO: Estudio de cohorte retrospectivo. 
MARCO: Centro de referencia para enfermedad inflamatoria intestinal.

PACIENTES: todos los pacientes adultos con EII diagnosticados con cáncer rectal, consecutives, y al menos un año de seguimiento postoperatorio se incluyeron y se emparejaron de manera 1: 2 (edad, sexo, etapa preoperatoria) con pacientes con cáncer rectal sin EII.

MEDIDAS DE RESULTADO PRINCIPALES: Se midieron la supervivencia general a cinco años y la supervivencia libre de enfermedad, complicaciones postoperatorias a los 30 días, reingreso, reoperación y tasas de mortalidad.

MÉTODOS: Las tasas de supervivencia se calcularon utilizando estimaciones de Kaplan-Meier. La asociación de factores de riesgo y resultados a largo plazo se evaluó mediante modelos de riesgo de proporción de Cox.

RESULTADOS: Un total de 107 pacientes con EII y cáncer rectal se compararon con 215 pacientes de control; las etapas preoperatorias fueron las siguientes: $31 \%$ de Etapa I, 19\% de Etapa II, 40\% de Etapa III y 10\% de Etapa IV. Se observaron diferencias (EII versus no EII) en quimioterapia neoadyuvante $(33.6 \%$ frente a $52.6 \%, p=0.001)$ y radioterapia preoperatoria $(35.5 \%$ frente a $53.5 \%, p=0.003)$. Las tasas de complicaciones postoperatorias fueron similares. En la patología quirúrgica, los pacientes con EII tuvieron más invasión linfovascular $(12.9 \%$ frente a $5.6 \%, p=0.04) \mathrm{y}$ márgenes de resección circunferencial positivos $(5.4 \%$ frente a $0.9 \%, p=0.03)$. En el análisis multivariable, el diagnóstico de EII no tuvo un impacto significativo en la mortalidad a largo plazo (HR 0.91; IC del 95\%: 0.53-1.57, $p=0.73$ ) o la supervivencia libre de enfermedad (HR 1.36; IC del 95\%: 0.84-2.21, $p=0.22$ )

LIMITACIONES: Diseño retrospectivo, centro único de datos.

CONCLUSIONES: Los pacientes con EII y sin EII con cáncer rectal tienen una supervivencia similar a largo plazo y libre de enfermedad, a pesar de las tasas más bajas de tratamiento sneoadyuvante y un mayor margen positivo en pacientes con EII. Consulte Video Resumen en http://links.lww.com/DCR/B271. (Traducción-Dr. Yesenia Rojas-Kahlil)

KEY WORDS: Complications; Inflammatory bowel disease; Rectal cancer; Survival.

$\mathrm{P}$ atients with IBD are at significantly increased risk for colorectal cancer (CRC), likely because of chronic intestinal inflammation resulting in mucosal changes that lead to dysplasia and subsequent invasive carcinoma. In patients with ulcerative colitis (UC), the estimated annual risk of CRC is $0.3 \%$ with a cumulative risk of $18.4 \%$ after 30 years. ${ }^{1}$ In Crohn's disease (CD), the estimated risk of CRC is $2.9 \%$ at 10 years, $5.6 \%$ at 20 years, and $8.3 \%$ at 30 years, ${ }^{2}$ with a 4.5 times higher risk in those with Crohn's colitis. ${ }^{2}$ Reported risk factors for CRC in IBD include extensive disease, ${ }^{1,3}$ young age at diagnosis, ${ }^{4}$ family history of CRC, ${ }^{5}$ coexisting primary sclerosing cholangitis, ${ }^{6}$ and persistent inflammation in the colon. ${ }^{7-9}$

The true rate of progression from low-grade dysplasia to high-grade dysplasia and subsequent invasive adenocarcinoma remains unknown. Molecular mechanisms involved in colitis-associated colorectal carcinoma development differ from those in sporadic CRC, reflecting the prominent role of inflammation-induced carcinogenesis. According to recent evidence, the inflammatory process in IBD represents a favorable microenvironment for selection and growth of a subpopulation of stem cells that are able to initiate and maintain colitis-associated cancer. ${ }^{10}$ With endoscopy continuing to evolve with high definition and chromoendoscopy, recommendations for colectomy versus ongoing surveillance in the setting of dysplasia have been updated, with a greater focus on continued screening in the setting of visible lesions with dysplasia. ${ }^{11}$ Over the past 4 decades, there have been small series looking at the 5 -year CRC survival rates in both UC and CD with overall rates ranging from $33.5 \%$ to $55.1 \%$ for $\mathrm{UC}^{12-16}$ and $18 \%$ to $46 \%$ in $\mathrm{CD}^{15,17}$ Although some of these studies reported no significant differences in survival when compared to non-IBD cases, other single-center, ${ }^{18,19}$ multicenter, ${ }^{20}$ population-based studies, and meta-analyse ${ }^{21}$ have found an increased mortality among patients with IBD who have CRC compared with patients who do not have IBD. ${ }^{22}$

Despite the extensive literature on incidence, risk factors, and survival of CRC in patients with IBD, rectal cancer has not been independently investigated separately from colon cancer. However, specific analysis of rectal cancer is warranted because of the differences in treatment protocols, survival outcomes, and quality-of-life implications in comparison with colon cancer. We therefore queried our prospectively maintained cancer registry to determine 1) 5-year overall survival, 2) 5-year disease-free survival, and 3) 30-day postoperative morbidity, mortality, readmission, and reoperation rates in patients who have rectal cancer with IBD versus without IBD.

\section{METHODS}

Following Institutional Review Board approval, our prospectively maintained cancer registry database was used to identify all adult patients ( $\geq 18$ years of age) with a histopathologic diagnosis of rectal cancer between January 2, 2000, and December 31, 2016. Patients included were those with at least 1 year of post-rectal cancer treatment follow-up. Patients with nonadenocarcinoma rectal cancer (eg, squamous cell, melanoma) or who had treatment performed at an outside hospital were excluded. The study 
group comprised all adult patients with a previous clinical, radiographic, or endoscopic diagnosis of IBD with a tissue diagnosis of rectal cancer. Patients with pretreatment stage 0 disease ( $\mathrm{T}$ in situ) were excluded. Each study patient with IBD was matched by age ( \pm 5 years), inclusion period $( \pm 2$ years), sex, and rectal cancer pretreatment TNM stage ${ }^{23}$ in a 1:2 fashion with a patient without IBD.

Data collected included patient demographics (age, sex, ASA class, smoking status (current/none), BMI); preoperative rectal cancer staging (local staging based on endoscopic ultrasound and MRI; tumor height (distance from anal verge to inferior tumor margin on MRI); CEA levels; systemic staging with CT chest, abdomen, and pelvis; and biologic exposure within 12 weeks of surgery, immunomodulator exposure within 4 weeks of surgery, or corticosteroid exposure within 4 weeks of surgery in patients with IBD); neoadjuvant treatment for rectal cancer (neoadjuvant chemotherapy and radiation therapy); pathologic features at the time of oncological surgical resection (TNM stage, grade of differentiation, presence of lymphovascular and perineural invasion, lymph node harvest and positivity, circumferential resection margin (CRM) status); 30-day postoperative complications (surgical site infection, anastomotic leak, deep venous thrombosis, urinary tract infection, pneumonia, small-bowel obstruction/ileus as defined by reinsertion of nasogastric tube for decompression); 30-day unplanned hospital readmission and reoperation rates; the use of adjuvant therapy (chemotherapy and additional radiation); and survival rates (disease-free survival and overall survival). For patients with IBD, the degree of inflammation was stratified as inactive, mild, or moderate according to preoperative endoscopic assessment. Thirty-day infectious complications included superficial surgical site infection, deep space infection, anastomotic leak, urinary tract infection, and pneumonia. Thirty-day surgical infectious complications included superficial surgical site infection, deep space infection, anastomotic leak, whereas nonsurgical infectious complications included urinary tract infection and pneumonia.

Treatment strategies were discussed for every patient at multidisciplinary tumor boards. Oncological treatment protocols utilized were consistent with recommendations published in the National Comprehensive Cancer Network guidelines. ${ }^{24}$ Perioperative care was standardized throughout the inclusion period (with implementation of an enhanced recovery protocol as a new division standard in 2011) and did not differ between patients with IBD and without IBD.

The primary outcomes were the overall and the disease-free survival rates of patients with IBD versus without IBD as estimated by Kaplan-Meier curves and multivariable Cox regression analysis. Secondary outcomes included short-term 30-day postoperative infectious complications, readmission, reoperation, and mortality rates.

\section{Statistical Analysis}

Chi-squared tests and unequal variance 2-sample $t$ test were used to compare patients with IBD and without IBD for categorical demographics and surgical variables. Wilcoxon tests were used to compare both groups for continuous variables, age and BMI. Logistic regression was used to examine the odds of 30-day outcomes given the patient has IBD. Odds ratio and Wald $p$ values were reported for 30-day outcome logistic regression models. Overall survival and disease-free survival where estimated with the Kaplan-Meier survival method. The study had an $80 \%$ power to detect a $\mathrm{HR}$ of $\geq 1.91$ for comparison of IBD vs non-IBD for overall survival and HR $\geq 1.94$ for progression-free survival. This is calculated based on the number of events. The association of risk factors, including IBD, and the risk of patient death and progression were assessed using Cox models. The $\alpha$-level was set at $p<0.05$ for statistical significance. The data analysis was generated using SAS software v9.4 (SAS Institute, Inc; Cary, NC).

\section{RESULTS}

A total of 107 study patients with IBD who have rectal cancer met inclusion criteria and were matched to 215 control patients. The median age of all patients was 53 years (range, $23-88$ years) and $71 \%$ were men. Patients without IBD were more likely to be smokers $(14.0 \%$ vs $6.5 \%, p=0.06$ ), but BMI and ASA status in patients with IBD and without IBD was not different (Table 1). Among patients with $\mathrm{CD}$, the majority of patients had primarily small-bowel distribution $(13 / 28,46 \%)$, whereas 7 patients $(25 \%)$ had primary colonic involvement.

On preoperative evaluation of rectal cancer, $31 \%$ had stage I, $19 \%$ had stage II, $40 \%$ had stage III and $10 \%$ had stage IV, with no significant differences between the 2 groups. Predominant sites of metastatic disease were liver (IBD group: 6/11 (55\%) vs control group: 14/22 (64\%); lung $(2 / 11(18 \%)$ vs $6 / 22(27 \%)$ and distant lymph nodes $(3 / 11(27 \%)$ vs $2 / 22(9 \%))$. Over $90 \%$ of primary tumors were found on endoscopic evaluation (Table 2).

Thirty patients with IBD $(28 \%)$ had a prior colorectal resection (of which 10 were subtotal or extended colectomies, 8 small-bowel resections, 5 ileocecal resections, 2 sigmoidectomies, and 5 other procedures).

Neoadjuvant treatment was less often performed in patients with IBD (Table 2) than in the control group. More specifically, the rate of neoadjuvant chemotherapy for stage II disease was $28.6 \%$ (6/21 patients) in the IBD group and $60.0 \%$ (24/40 patients) in the control group. For stage III disease, the rate was $53.5 \%$ (23/43 patients) in the IBD group and $87.2 \%$ (75/86 patients) in the control group.

There were no significant differences in 30-day postoperative outcomes, readmission, reoperation rates, or mortal- 
TABLE 1. Demographics and surgical details

\begin{tabular}{|c|c|c|c|c|}
\hline Variable & $I B D(n=107)$ & No IBD $(n=215)$ & Total $(n=322)$ & $p$ value \\
\hline Age, median (range) & $54(25-83)$ & $53(23-88)$ & $53(23-88)$ & 0.420 \\
\hline Female, n (\%) & $31(29.0)$ & $62(28.8)$ & $93(28.9)$ & 1.000 \\
\hline ASA classification, n (\%) & & & & 0.888 \\
\hline Missing & 55 & 74 & 129 & \\
\hline 1 & $4(7.7)$ & $8(5.7)$ & $12(6.2)$ & \\
\hline ॥ & $37(71.2)$ & $103(71.6)$ & $138(71.5)$ & \\
\hline III & $11(21.2)$ & $32(22.7)$ & $43(22.3)$ & \\
\hline Tobacco use, n (\%) & $7(6.5)$ & $30(14.0)$ & $37(11.5)$ & 0.063 \\
\hline BMI, median (range) & $27.3(18-42.6)$ & $27.1(12.8-49.5)$ & $27.1(12.8-49.5)$ & 0.971 \\
\hline Ethnicity, n (\%) & & & & 0.645 \\
\hline Other & $5(4.7)$ & $11(5.1)$ & $16(5.0)$ & \\
\hline White & $102(95.3)$ & $204(94.9)$ & $306(95.0)$ & \\
\hline \multicolumn{5}{|l|}{ UC/CD, n (\%) } \\
\hline$C D$ & $28(26.2)$ & & & \\
\hline UC & $79(73.8)$ & & & \\
\hline Duration of IBD, $y$, median (range) & $27.0(0.0-61.0)$ & & & \\
\hline \multicolumn{5}{|l|}{ Disease activity (inflammation), $\mathrm{n}(\%)$} \\
\hline Inactive & $19(27.1)$ & & & \\
\hline Mild & $26(37.1)$ & & & \\
\hline Moderate & $25(35.7)$ & & & \\
\hline Missing & 37 & & & \\
\hline Corticosteroids, n (\%) & $13(12.4)$ & & & \\
\hline Biologics, n (\%) & $10(9.5 \%)$ & & & \\
\hline Immunomodulators, $\mathrm{n}(\%)$ & $13(12.4 \%)$ & & & \\
\hline Type of surgery, $\mathrm{n}(\%)$ & & & & $<0.001$ \\
\hline APR & $33(30.8)$ & $62(28.8)$ & $95(29.5)$ & \\
\hline LAR & $3(2.8)$ & $128(59.5)$ & $131(40.7)$ & \\
\hline TPC & $57(53.3)$ & $6(2.8)$ & $63(19.6)$ & \\
\hline Transanal excision & $14(13.1)$ & $19(8.8)$ & $33(10.2)$ & \\
\hline Diversion, $\mathrm{n}(\%)$ & $18(16.8)$ & $88(40.9)$ & $106(32.9)$ & $<0.001$ \\
\hline Laparoscopy, n (\%) & $33(30.8)$ & $75(34.9)$ & $108(33.5)$ & 0.469 \\
\hline
\end{tabular}

$\mathrm{APR}=$ abdominoperineal resection; $\mathrm{CD}=$ Crohn's disease; $\mathrm{IQR}=$ interquartile range; $\mathrm{LAR}=$ low anterior resection; $\mathrm{TPC}=$ total proctocolectomy; $\mathrm{UC}=\mathrm{ulcerative}$ colitis.

ity rates following rectal cancer surgery in patients with IBD versus patients without IBD. These included surgical site infection $(p=0.50)$, deep space infection $(p=0.62)$, anastomotic leak $(p=0.28)$, urinary tract infection $(p=0.75)$, pneumonia $(p=0.20)$, any infectious complication $(p=0.80)$, deep vein thrombosis $(p=0.86)$, small-bowel obstruction $(p=0.75)$, and 30-day mortality $(p=0.85)$ (Table 3$)$.

On surgical pathology, there were no significant differences in TNM stage, tumor differentiation, presence of perineural invasion, or lymph node positivity (all $p>0.05$ ). However, patients with IBD had significantly increased rates of lymphovascular invasion $(12.9 \%$ vs $5.6 \%$, $p=0.04)$ and positive CRM status $(5.4 \%$ vs $0.9 \%$, $p=0.03$ ) (Table 4). More specifically, positive margins were found in 2 patients with stage I disease $(1(3.3 \%)$ in the IBD group) vs 1 (1.5\%) in the control group), 2 patients with stage II disease (2 (10\%) vs 0$), 2$ patients with stage III disease (2 (5.1\%) vs 0$)$, and 1 patient with stage

TABLE 2. Preoperative evaluation and oncological treatment of rectal cancer

\begin{tabular}{|c|c|c|c|c|}
\hline Variable & $\operatorname{IBD}(n=107)$ & No IBD $(n=215)$ & Total $(n=322)$ & $p$ value \\
\hline Preoperative overall stage, n (\%) & & & & 0.994 \\
\hline 1 & $32(29.9)$ & $67(31.2)$ & $99(30.8)$ & \\
\hline 2 & $21(19.6)$ & $40(18.6)$ & $61(18.9)$ & \\
\hline 3 & $43(40.2)$ & $86(40.0)$ & $129(40.1)$ & \\
\hline 4 & $11(10.3)$ & $22(10.2)$ & $33(10.2)$ & \\
\hline Tumor height, $<6 \mathrm{~cm}$ from anal verge, $\mathrm{n}(\%)$ & $48(44.9)$ & $83(38.6)$ & $131(40.7)$ & \\
\hline Found on endoscopy, $\mathrm{n}(\%)$ & $96(89.7)$ & $203(94.4)$ & $299(92.9)$ & 0.167 \\
\hline Found on imaging, $\mathrm{n}(\%)$ & $4(3.7)$ & $13(6.0)$ & $17(5.3)$ & 0.442 \\
\hline Neoadjuvant radiation, $\mathrm{n}(\%)$ & $38(35.5)$ & $115(53.5)$ & $153(47.5)$ & 0.003 \\
\hline Neoadjuvant chemotherapy, n (\%) & $36(33.6)$ & $113(52.6)$ & $149(46.3)$ & 0.001 \\
\hline Adjuvant chemotherapy, $\mathrm{n}(\%)$ & $49(45.8)$ & $121(56.3)$ & $170(52.8)$ & 0.083 \\
\hline
\end{tabular}

Details regarding tumor stage, location and diagnosis, and neoadjuvant and adjuvant treatment strategies. 
IV disease ( 0 vs $1(4.5 \%)$ ). The rate of local recurrence was $6.5 \%(7 / 107$ cases) in the IBD group and 5.1\% (11/215 cases) in the control group.

Overall median follow-up of the entire cohort was 2.96 (interquartile range (IQR) 1.19-5.81) years for overall survival (IBD group: 2.35 (IQR 0.64-5.84) years; control group: 3.30 (IQR 1.58-5.81) years) and 2.11 (IQR 0.65-4.99) years for disease-free survival (IBD group: 1.68 (IQR 0.34-3.98) years; control group: 2.34 (IQR 0.755.06) years). Overall, 3-year survival rates for patients with IBD and without IBD with rectal cancer were $73.1 \%$ and $82.5 \%$; and, at 5 years, $69.6 \%$ and $74.5 \%$. Patients who had rectal cancer with IBD had a nonsignificantly increased overall mortality compared with patients without IBD (HR, 1.29; 95\% CI, 0.83-2.02; $p=0.27$ ) (Table 5, Fig. 1). On multivariable analysis, there were no significant predictors of 5-year overall survival including the diagnosis of IBD (HR, 0.91; 95\% CI, 0.53-1.57; $p=0.73$ ). Overall 3-year disease-free survival in patients with IBD and without IBD was $61.7 \%$ and $74.7 \%$, and 5 -year disease-free survival in patients with IBD and without IBD was $55.8 \%$ and $69.9 \%$. On multivariable analysis, the diagnosis of IBD did not significantly affect disease-free survival (HR, 1.36; 95\% CI, $0.84-2.21 ; p=0.22$ ), but pathologic stages III and IV were associated with significantly decreased disease-free survival (HR, 4.23; 95\% CI, 1.94-9.24; $p=0.0001)$ and (HR, 12.85; 95\% CI, 3.69-44.77; $p=0.0001$ ) (Table 6, Fig. 2).

\section{DISCUSSION}

There is now extensive literature on the increased risk for CRC in patients with IBD, and the potential for increased

TABLE 3. Thirty-day complications

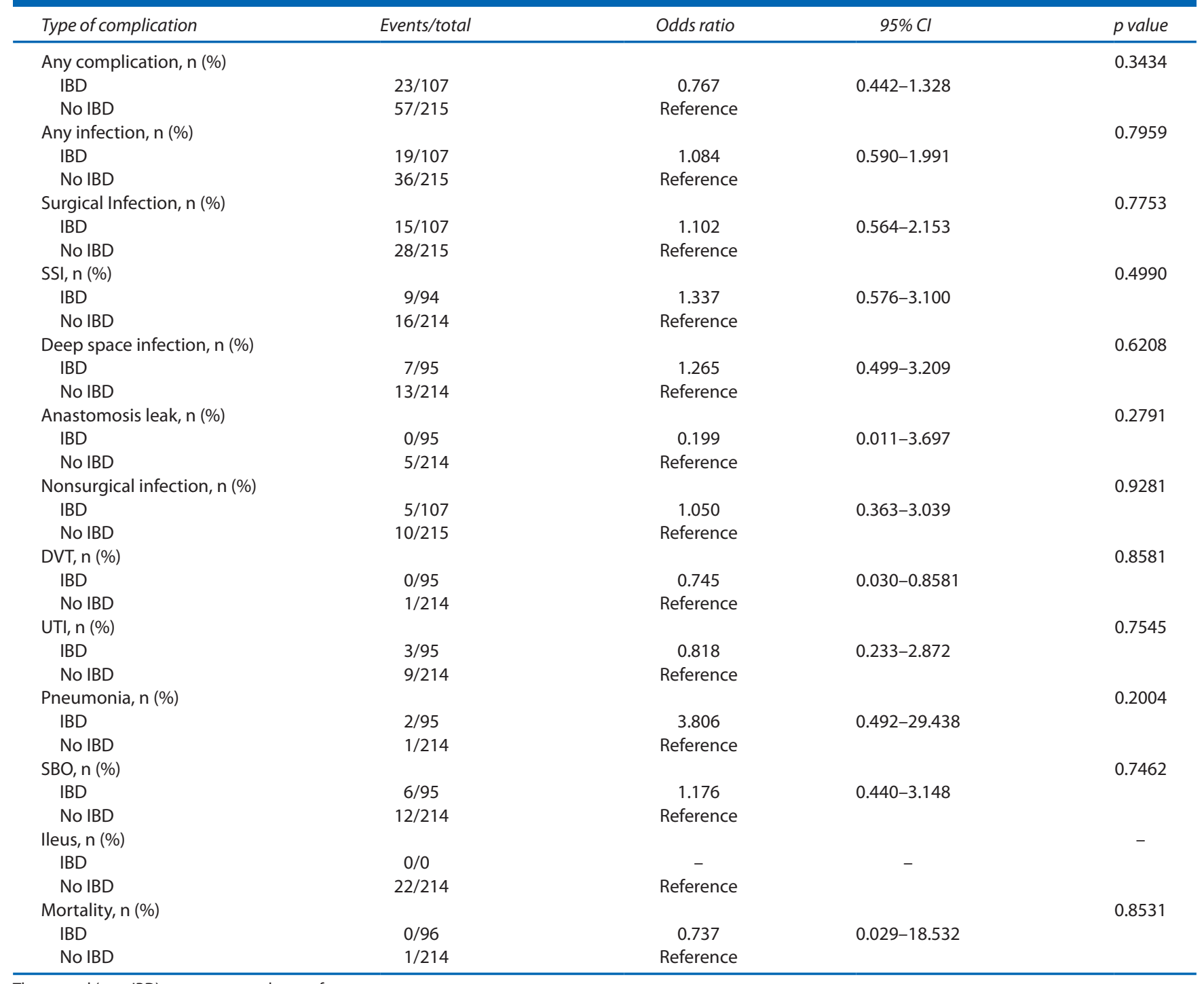

The control (non-IBD) group was used as a reference.

$\mathrm{DVT}=$ deep vein thrombosis; $\mathrm{SBO}=$ small-bowel obstruction; $\mathrm{SSI}$ = surgical site infection; $\mathrm{UTI}=$ urinary tract infection. 
TABLE 4. Surgical pathology

\begin{tabular}{|c|c|c|c|c|}
\hline Variable & $I B D(n=107)$ & No IBD $(n=215)$ & Total $(n=322)$ & $p$ value \\
\hline Differentiation, $\mathrm{n}(\%)$ & & & & 0.384 \\
\hline Missing & 14 & 1 & 15 & \\
\hline Moderately & 35 (37.6) & $66(30.8)$ & $101(32.9)$ & \\
\hline Poorly & $43(46.2)$ & $117(54.7)$ & $10(52.1)$ & \\
\hline Well & $15(16.1)$ & $31(14.5)$ & $46(15)$ & \\
\hline LVI, n (\%) & & & & 0.029 \\
\hline Missing & 14 & 1 & 15 & \\
\hline No & $81(87.1)$ & $202(94.4)$ & $283(92.2)$ & \\
\hline Yes & $12(12.9)$ & $12(5.6)$ & $24(7.8)$ & \\
\hline Margins (CRM), $\mathrm{n}(\%)$ & & & & 0.029 \\
\hline Missing & 14 & 1 & 15 & \\
\hline Margins Involved & $5(5.4)$ & $2(0.9)$ & $7(2.3)$ & \\
\hline Negative & $88(94.6)$ & $212(99.1)$ & $300(97.7)$ & \\
\hline PNI, n (\%) & & & & 0.437 \\
\hline Missing & 14 & 0 & 14 & \\
\hline No & $93(96.8)$ & $210(98.1)$ & $300(97.7)$ & \\
\hline Yes & $3(3.2)$ & $4(1.9)$ & $7(2.3)$ & \\
\hline Overall pathology stage, n (\%) & & & & 0.109 \\
\hline Missing & 16 & 1 & 17 & \\
\hline 0 & $9(9.9)$ & $28(13.2)$ & $37(12.1)$ & \\
\hline 1 & $30(33.0)$ & $72(33.6)$ & $102(33.4)$ & \\
\hline $2 \mathrm{~A}$ & $15(16.5)$ & $30(14.0)$ & 45 (14.7) & \\
\hline $2 B$ & $3(3.3)$ & $6(2.8)$ & $9(3.0)$ & \\
\hline $3 \mathrm{~A}$ & $2(2.2)$ & $22(10.3)$ & $24(7.9)$ & \\
\hline $3 B$ & $15(16.5)$ & $23(10.7)$ & $38(12.5)$ & \\
\hline $3 C$ & $11(12.1)$ & $12(5.6)$ & $23(7.5)$ & \\
\hline 4 & $6(6.5)$ & $21(9.8)$ & $27(8.9)$ & \\
\hline Pathology stage simplified, n (\%) & & & & 0.760 \\
\hline Missing & 16 & 1 & 17 & \\
\hline 0 & $9(9.9)$ & $28(13.2)$ & $37(12.1)$ & \\
\hline 1 & $30(33.0)$ & $72(33.6)$ & $102(33.4)$ & \\
\hline 2 & $18(19.8)$ & $36(16.8)$ & $54(17.7)$ & \\
\hline 3 & $28(30.8)$ & $57(26.6)$ & $85(27.9)$ & \\
\hline 4 & $6(6.5)$ & $21(9.8)$ & $27(8.9)$ & \\
\hline
\end{tabular}

$\mathrm{CRM}=$ circumferential resection margin; $\mathrm{LVI}=$ lymphovascular invasion; $\mathrm{PNI}$ = perineural invasion.

mortality. ${ }^{3,25,26}$ However, survival differences in patients with IBD and without IBD with isolated rectal cancer remains unreported. Because treatment paradigms continue to evolve for rectal cancer, including trials of all adjuvant therapy completed preoperatively ${ }^{27}$ or watch and wait protocols, ${ }^{28}$ it is important to report any potential treatment and survival differences in patients with IBD to highlight areas for optimization of treatment protocols. We found no significant differences in overall survival and diseasefree survival between patients with IBD and without IBD. Three-year and 5-year overall survival in patients with IBD and without IBD were $73 \%$ and $83 \%$ and $70 \%$ and $75 \%$. The 3 - and 5-year disease-free survival rates were $62 \%$ and $75 \%$ and $56 \%$ and $70 \%$. The relative differences seen may be a reflection of the decreased use of neoadjuvant treatment and increased positive circumferential margin status at the time of oncological resection in the IBD cohort.

Previous reports from Mayo Clinic on IBD-associated CRC found that the 5-year survival rates were 54\% in the IBD-CRC subgroup and $53 \%$ in the sporadic CRC subgroup. ${ }^{29}$ The lack of survival difference among 241 patients with UC and 49 patients with CD matched by age and sex to sporadic cancers may have been related to only one-third of the cancers being rectal cancer, or an increased proportion of proximal cancer in patients with IBD; it may also be a reflection of over half of the cancers being stage I/II representing an earlier stage with improved survival. ${ }^{29}$ However, in an even larger multicenter study of 371 patients who had IBD with CRC compared with 52,243 patients who did not have IBD with CRC, IBD status again did not significantly influence overall survival. ${ }^{30}$ However, other large multicenter and populationbased $^{18,22,31,32}$ studies have reported a trend or significant decrease in overall survival in patients with IBD who had CRC in comparison with patients without IBD, even when matched by age, sex, and stage at diagnosis, as it was done in our analysis. ${ }^{18}$ Thus, our finding of no significant differences in overall and disease-free survival are comparable to previous findings in the CRC literature, even when analyzing rectal cancer in isolation. 
TABLE 5. Overall survival

\begin{tabular}{|c|c|c|c|c|c|c|c|}
\hline & $\underline{\text { Events/total }}$ & $\begin{array}{c}\text { Kaplan-Meier } \\
\text { estimates }\end{array}$ & $\begin{array}{l}\text { Univariate } \\
\text { Cox model }\end{array}$ & & $\underline{\text { Events/total }}$ & $\begin{array}{c}\text { Multivariable } \\
\text { Cox model }\end{array}$ & \\
\hline Variable & $x / n$ & At 5 y $(95 \% \mathrm{Cl})$ & $H R(95 \% \mathrm{Cl})$ & $p$ value & $x / n$ & $H R(95 \% \mathrm{Cl})$ & $p$ value \\
\hline Overall & $86 / 322$ & $73 \%(67-79)$ & & & $76 / 305$ & & \\
\hline IBD & & & & $0.2663^{1}$ & & & $0.7279^{1}$ \\
\hline IBD & $31 / 107$ & $70 \%(60-81)$ & $1.29(0.83-2.02)$ & & $22 / 91$ & $0.91(0.53-1.57)$ & \\
\hline No IBD & $55 / 215$ & $74 \%(68-82)$ & Reference & & $54 / 214$ & Reference & \\
\hline $\mathrm{UC} / \mathrm{CD}$ & & & & $0.4761^{1}$ & & & \\
\hline$C D$ & $9 / 28$ & $73 \%(56-95)$ & $1.13(0.55-2.30)$ & & & & \\
\hline UC & $22 / 79$ & $68 \%(56-82)$ & $1.37(0.83-2.26)$ & & & & \\
\hline No IBD & $55 / 215$ & $74 \%(68-82)$ & Reference & & & & \\
\hline Sex & & & & $0.2907^{1}$ & & & $0.6317^{1}$ \\
\hline $\mathrm{F}$ & $25 / 93$ & $68 \%(56-81)$ & Reference & & $22 / 88$ & Reference & \\
\hline M & $61 / 229$ & $75 \%(68-82)$ & $0.77(0.48-1.23)$ & & $54 / 217$ & $1.14(0.66-1.98)$ & \\
\hline Margins & & & & $0.0623^{1}$ & & & $0.7569^{1}$ \\
\hline Margins involved & $4 / 7$ & $50 \%(22-100)$ & $3.09(1.12-8.54)$ & & $4 / 7$ & $1.23(0.34-4.42)$ & \\
\hline Negative & $72 / 300$ & $76 \%(71-82)$ & Reference & & $72 / 298$ & Reference & \\
\hline Preoperative overall stage & & & & $<.0001^{1}$ & & & $0.2612^{1}$ \\
\hline 1 & $15 / 99$ & $88 \%(80-96)$ & Reference & & $14 / 96$ & Reference & \\
\hline 2 & $15 / 61$ & $71 \%(58-86)$ & $2.58(1.24-5.38)$ & & $14 / 60$ & $1.74(0.64-4.73)$ & \\
\hline 3 & $33 / 129$ & $79 \%(71-88)$ & $2.06(1.10-3.85)$ & & $30 / 123$ & $1.40(0.56-3.49)$ & \\
\hline 4 & $23 / 33$ & $17 \%(6-43)$ & $11.77(5.87-23.59)$ & & $18 / 26$ & $3.25(0.95-11.07)$ & \\
\hline Pathology stage & & & & $<.0001^{1}$ & & & $0.1282^{1}$ \\
\hline 0 & $6 / 37$ & $84 \%(70-100)$ & $1.40(0.53-3.69)$ & & $6 / 37$ & $1.29(0.47-3.55)$ & \\
\hline 1 & $14 / 102$ & $89 \%(82-97)$ & Reference & & $14 / 102$ & Reference & \\
\hline 2 & $15 / 54$ & $72 \%(58-89)$ & $3.02(1.41-6.43)$ & & $15 / 54$ & $2.19(0.90-5.36)$ & \\
\hline 3 & $21 / 85$ & $76 \%(66-88)$ & $2.35(1.17-4.73)$ & & $21 / 85$ & $1.91(0.85-4.28)$ & \\
\hline 4 & $20 / 27$ & $30 \%(16-56)$ & $11.07(5.34-22.92)$ & & $20 / 27$ & $4.51(1.45-13.96)$ & \\
\hline Neoadjuvant chemotherapy & & & & $0.2299^{1}$ & & & $0.6961^{1}$ \\
\hline No & $42 / 173$ & $74 \%(0.67-83)$ & Reference & & $37 / 164$ & Reference & \\
\hline Yes & $44 / 149$ & $71 \%(0.63-81)$ & $1.30(0.85-2.00)$ & & $39 / 141$ & $1.20(0.48-3.01)$ & \\
\hline Neoadjuvant radiation & & & & $0.4563^{1}$ & & & $0.6553^{1}$ \\
\hline No & $43 / 169$ & $73 \%(65-82)$ & Reference & & $38 / 160$ & Reference & \\
\hline Yes & $43 / 153$ & $73 \%(65-82)$ & $1.18(0.77-1.81)$ & & $38 / 145$ & $0.81(0.32-2.04)$ & \\
\hline LVI & & & & $0.0160^{1}$ & & & $0.1820^{1}$ \\
\hline No & $66 / 283$ & $77 \%(71-83)$ & Reference & & $66 / 282$ & Reference & \\
\hline Yes & $10 / 24$ & $61 \%(42-89)$ & $2.51(1.28-4.93)$ & & $10 / 23$ & $1.79(0.79-4.04)$ & \\
\hline PNI & & & & $0.0193^{1}$ & & & \\
\hline No & $72 / 300$ & $76 \%(71-82)$ & Reference & & & & \\
\hline Yes & $4 / 7$ & $32 \%(7-100)$ & $4.40(1.58-12.23)$ & & & & \\
\hline Type of operation & & & & $0.5030^{1}$ & & & \\
\hline APR & $30 / 95$ & $72 \%(61-84)$ & $1.28(0.78-2.11)$ & & & & \\
\hline LAR & $33 / 131$ & $74 \%(66-84)$ & Reference & & & & \\
\hline TPC & $14 / 63$ & $74 \%(62-89)$ & $0.83(0.43-1.58)$ & & & & \\
\hline Transanal excision & $9 / 33$ & $69 \%(52-90)$ & $1.32(0.63-2.77)$ & & & & \\
\hline Adjuvant chemotherapy & & & & $0.4296^{1}$ & & & \\
\hline No & $31 / 129$ & $80 \%(72-89)$ & $0.83(0.53-1.32)$ & & & & \\
\hline Yes & $47 / 170$ & $72 \%(65-80)$ & Reference & & & & \\
\hline Age, $y$ & $86 / 322$ & $73 \%(67-79)$ & $1.03(1.01-1.05)$ & $0.0022^{1}$ & & & \\
\hline
\end{tabular}

Univariate and multivariable Cox regression models for overall survival.

$\mathrm{APR}=$ abdominoperineal resection; $\mathrm{CD}=$ Crohn's disease; $\mathrm{LAR}=$ low anterior resection; $\mathrm{LVI}=$ lymphovascular invasion; $\mathrm{PNI}=$ perineural invasion; $\mathrm{TPC}=$ total proctocolectomy; UC = ulcerative colitis.

Two prior population-based studies from Denmark have compared UC and $\mathrm{CD}^{31}$ specifically with regard to survival compared with patients without IBD. In the UC study, 279 UC CRC cases were compared with 71,259 sporadic non-IBD cases; cancer stage, rates of lymph node, and distant metastases were similar, but overall mortality at 1 and 5 years was higher in the UC group.
Similarly, when 100 CD CRC cases were compared with 71,435 sporadic non-IBD cases, the HRs for death at 1 and 5 years were both increased in patients with $\mathrm{CD} .{ }^{31}$ When studies have compared UC to $\mathrm{CD}$, patients with CD have been found to have worse survival outcomes. ${ }^{33}$ However, in another population-based study, rectal cancer in CD was a subgroup that was spared from the de- 
Percent Without Event

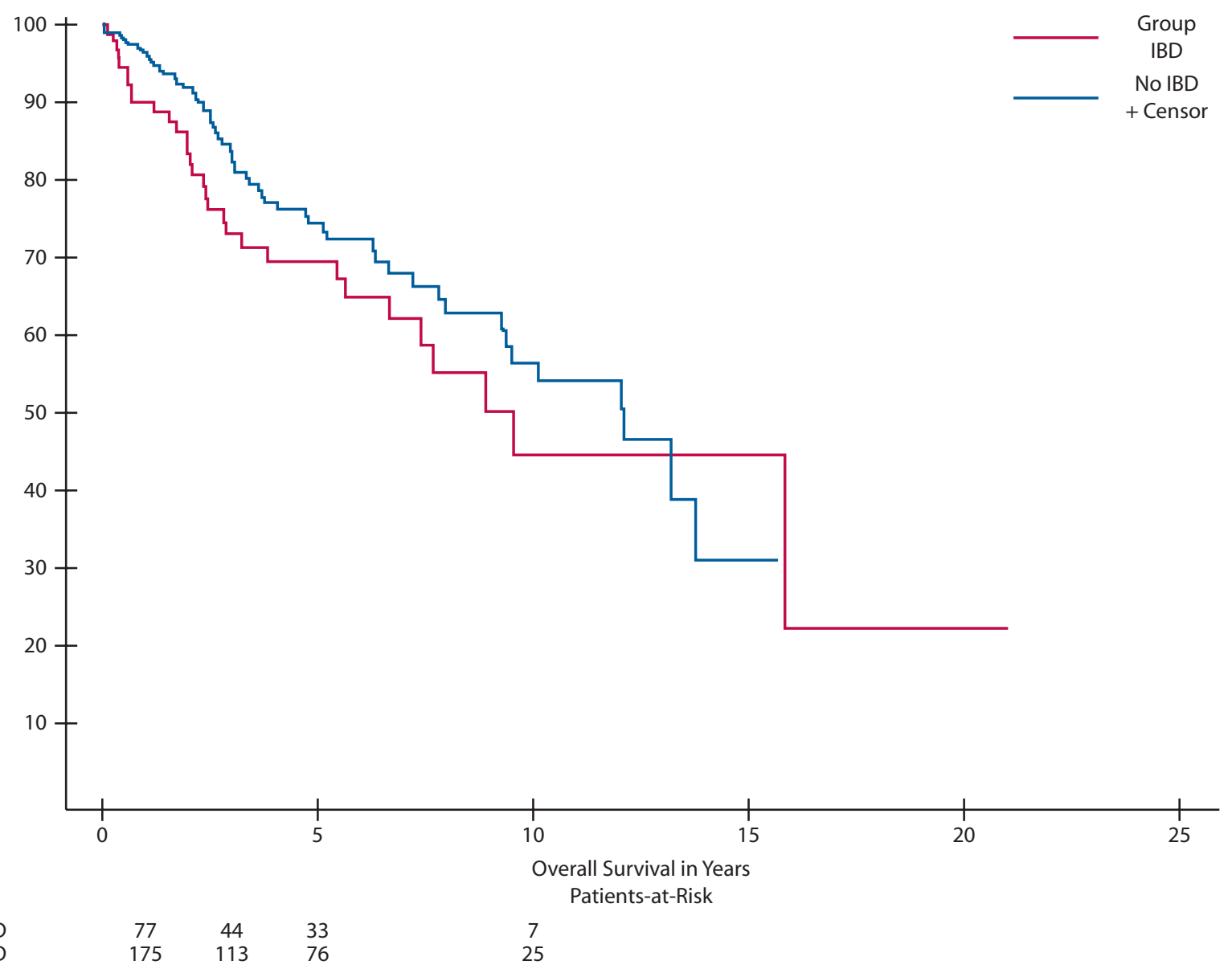

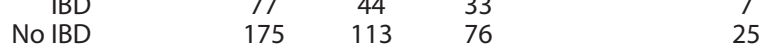

FIGURE 1. Kaplan-Meier overall survival comparing IBD cases vs controls. IBD status was associated with an increased, although nonsignificant, risk of death ( $\mathrm{HR}, 1.29 ; 95 \% \mathrm{Cl}, 0.83-2.02 ; p=0.26)$.

creased survival found in the IBD cohorts. ${ }^{19}$ Our series of 28 patients with CD and 79 patients with UC demonstrated no significant difference in overall 5 -year survival rates, which were $73 \%$ and $68 \%$ in patients with $C D$ and patients with UC (Table 5). However, we did find a significant decrease in the 5-year disease-free survival rate among patients with UC compared with the patients with CD (49\% vs $70 \%$, Table 6). However, these results need to be interpreted with caution considering the small sample size.

Neoadjuvant therapy has been associated with improved local control in patients with locally advanced rectal cancer, even when total mesorectal excision is performed. ${ }^{34}$ Although the classic, fractioned longcourse radiotherapy with radiosensitizing chemotherapy is still considered as the gold standard, short-course radiotherapy has been suggested as valid alternative because of the advantages in treatment compliance, safety, and cost. ${ }^{35}$ In our cohort, patients with IBD received less neoadjuvant therapy, despite similar tumor stage. Literature on rate and compliance with neoadjuvant therapy in patients with IBD who have rectal cancer is scarce, impeding meaningful comparison to our study. The lower rate observed in this present study compared to the control group may be explained by a lower threshold in patients with CD to withhold neoadjuvant therapy related to active disease, decreased general condition, and, potentially, understaging rectal cancer in the setting of inflammatory disease. Whether patients with IBD are potentially undertreated (higher CRM positivity rate, lower 5-year disease-free survival rate) needs to be further determined through studies with larger cohorts.

Even though not significant, this study found decreased disease-free survival in patients with IBD. This may also be related to decreased neoadjuvant therapy and positive circumferential margin status, with a concomitant increased risk of local or distant recurrence. ${ }^{36}$ Both items were retained as confounders in the multivariable model, which revealed tumor stage as most predictive for tumor progression.

There are several limitations worth mentioning. First, this is a retrospective review of a prospectively maintained database with inherent limitations. Second, 
TABLE 6. Disease-free survival

\begin{tabular}{|c|c|c|c|c|c|c|c|}
\hline & $\underline{\text { Events/total }}$ & $\begin{array}{c}\text { Kaplan-Meier } \\
\text { estimates }\end{array}$ & $\begin{array}{l}\text { Univariate } \\
\text { Cox model }\end{array}$ & & Events/total & $\begin{array}{c}\text { Multivariable } \\
\text { Cox model }\end{array}$ & \\
\hline Variable & $x / n$ & At 5 y $(95 \% \mathrm{Cl})$ & $H R(95 \% \mathrm{Cl})$ & $p$ value & $x / n$ & $H R(95 \% C l)$ & $p$ value \\
\hline Overall & $82 / 322$ & $65 \%(59-72)$ & & & $80 / 305$ & & \\
\hline $\mathrm{IBD}$ & & & & $0.0917^{1}$ & & & $0.2231^{1}$ \\
\hline IBD & $32 / 107$ & $56 \%(45-69)$ & $1.46(0.94-2.28)$ & & $31 / 91$ & $1.36(0.84-2.21)$ & \\
\hline No IBD & $50 / 215$ & $70 \%(63-78)$ & Reference & & $49 / 214$ & Reference & \\
\hline $\mathrm{UC} / \mathrm{CD}$ & & & & $0.0562^{1}$ & & & \\
\hline$C D$ & $6 / 28$ & $70 \%(53-94)$ & $0.84(0.36-1.97)$ & & & & \\
\hline UC & $26 / 79$ & $49 \%(36-67)$ & $1.76(1.10-2.83)$ & & & & \\
\hline No IBD & $50 / 215$ & $70 \%(63-78)$ & Reference & & & & \\
\hline Sex & & & & $0.1676^{1}$ & & & $0.6496^{1}$ \\
\hline $\mathrm{F}$ & $27 / 93$ & $61 \%(49-75)$ & Reference & & $26 / 88$ & Reference & \\
\hline$M$ & $55 / 229$ & $67 \%(60-75)$ & $0.72(0.45-1.14)$ & & $54 / 217$ & $0.89(0.53-1.48)$ & \\
\hline Margins & & & & $0.0069^{1}$ & & & $0.0854^{1}$ \\
\hline Margins involved & $5 / 7$ & $0(0-0)$ & $4.69(1.88-11.73)$ & & $5 / 7$ & $2.64(0.96-7.22)$ & \\
\hline Negative & $75 / 300$ & $67 \%(61-74)$ & Reference & & $75 / 298$ & Reference & \\
\hline Preoperative overall stage & & & & $0.0002^{1}$ & & & $0.6422^{1}$ \\
\hline 1 & $14 / 99$ & $81 \%(72-92)$ & Reference & & $14 / 96$ & Reference & \\
\hline 2 & $16 / 61$ & $59 \%(45-77)$ & $2.45(1.20-5.03)$ & & $16 / 60$ & $1.47(0.60-3.63)$ & \\
\hline 3 & $40 / 129$ & $62 \%(53-73)$ & $2.26(1.23-4.16)$ & & $38 / 123$ & $0.98(0.43-2.22)$ & \\
\hline 4 & $12 / 33$ & $35 \%(16-74)$ & $5.88(2.69-12.87)$ & & $12 / 26$ & $0.78(0.19-3.17)$ & \\
\hline Pathology stage & & & & $<.0001^{1}$ & & & $<.0001^{1}$ \\
\hline 0 & $4 / 37$ & $87 \%(76-100)$ & $0.99(0.31-3.16)$ & & $4 / 37$ & $0.97(0.29-3.19)$ & \\
\hline 1 & $10 / 102$ & $87 \%(80-96)$ & Reference & & $10 / 102$ & Reference & \\
\hline 2 & $17 / 54$ & $56 \%(42-75)$ & $3.54(1.62-7.73)$ & & $17 / 54$ & $2.87(1.16-7.08)$ & \\
\hline 3 & $34 / 85$ & $51 \%(40-66)$ & $4.57(2.26-9.26)$ & & $34 / 85$ & $4.23(1.94-9.24)$ & \\
\hline 4 & $15 / 27$ & $21 \%(8-55)$ & $11.75(5.23-26.39)$ & & $15 / 27$ & $12.85(3.69-44.77)$ & \\
\hline Neoadjuvant chemotherapy & & & & $0.3857^{1}$ & & & $0.3108^{1}$ \\
\hline No & $39 / 173$ & $68 \%(60-78)$ & Reference & & $39 / 164$ & Reference & \\
\hline Yes & $43 / 149$ & $63 \%(54-72)$ & $1.21(0.79-1.87)$ & & $41 / 141$ & $1.60(0.65-3.94)$ & \\
\hline Neoadjuvant radiation & & & & $0.7953^{1}$ & & & $0.5514^{1}$ \\
\hline No & $41 / 169$ & $67 \%(58-76)$ & Reference & & $41 / 160$ & Reference & \\
\hline Yes & $41 / 153$ & $64 \%(56-74)$ & $1.06(0.69-1.63)$ & & $39 / 145$ & $0.75(0.30-1.90)$ & \\
\hline LVI & & & & $0.0688^{1}$ & & & $0.3962^{1}$ \\
\hline No & $71 / 283$ & $67 \%(61-74)$ & Reference & & $71 / 282$ & Reference & \\
\hline Yes & $9 / 24$ & $51 \%(32-81)$ & $2.02(1.01-4.05)$ & & $9 / 23$ & $1.39(0.67-2.89)$ & \\
\hline PNI & & & & $0.0062^{1}$ & & & \\
\hline No & $75 / 300$ & $67 \%(61-74)$ & Reference & & & & \\
\hline Yes & $5 / 7$ & & $4.80(1.92-11.99)$ & & & & \\
\hline Type of operation & & & & $0.4558^{1}$ & & & \\
\hline APR & $28 / 95$ & $61 \%(50-75)$ & $1.31(0.79-2.18)$ & & & & \\
\hline LAR & $31 / 131$ & $70 \%(61-80)$ & Reference & & & & \\
\hline TPC & $18 / 63$ & $57 \%(44-75)$ & $1.35(0.76-2.42)$ & & & & \\
\hline Transanal excision & $5 / 33$ & $80 \%(64-100)$ & $0.74(0.29-1.91)$ & & & & \\
\hline Adjuvant chemotherapy & & & & $0.0197^{1}$ & & & \\
\hline No & $24 / 129$ & $75 \%(66-85)$ & $0.58(0.36-0.93)$ & & & & \\
\hline Yes & $56 / 170$ & $60 \%(52-69)$ & Reference & & & & \\
\hline Age, $y$ & $82 / 322$ & $65 \%(59-72)$ & $0.99(0.97-1.01)$ & $0.3388^{1}$ & & & \\
\hline
\end{tabular}

Univariate and multivariable Cox regression models for disease-free survival.

$\mathrm{APR}=$ abdominoperineal resection; $\mathrm{CD}=$ Crohn's disease; $\mathrm{LAR}=$ low anterior resection; $\mathrm{LVI}=$ lymphovascular invasion; $\mathrm{PNI}=$ perineural invasion; $\mathrm{TPC}=$ total proctocolectomy; UC = ulcerative colitis.

the data were derived from an IBD referral center, which impedes uncritical extrapolation of our results to other practice settings. Third, the limitation in sample size due to a focus on rectal cancer alone makes the study prone to type II error. Furthermore, other interesting subgroup analyses based on immunosuppressive medications, neoadjuvant treatment protocols were not pos- sible. Whether a bigger sample size would have led to a statistically significant difference cannot be determined, and larger cohorts analyzed in the future may reveal a potential survival difference. Fourth, specifics on oncological treatment were not available. Many treatment options including short-course and long-course radiation, varying chemotherapeutic protocols, and changes 
Percent Without Event

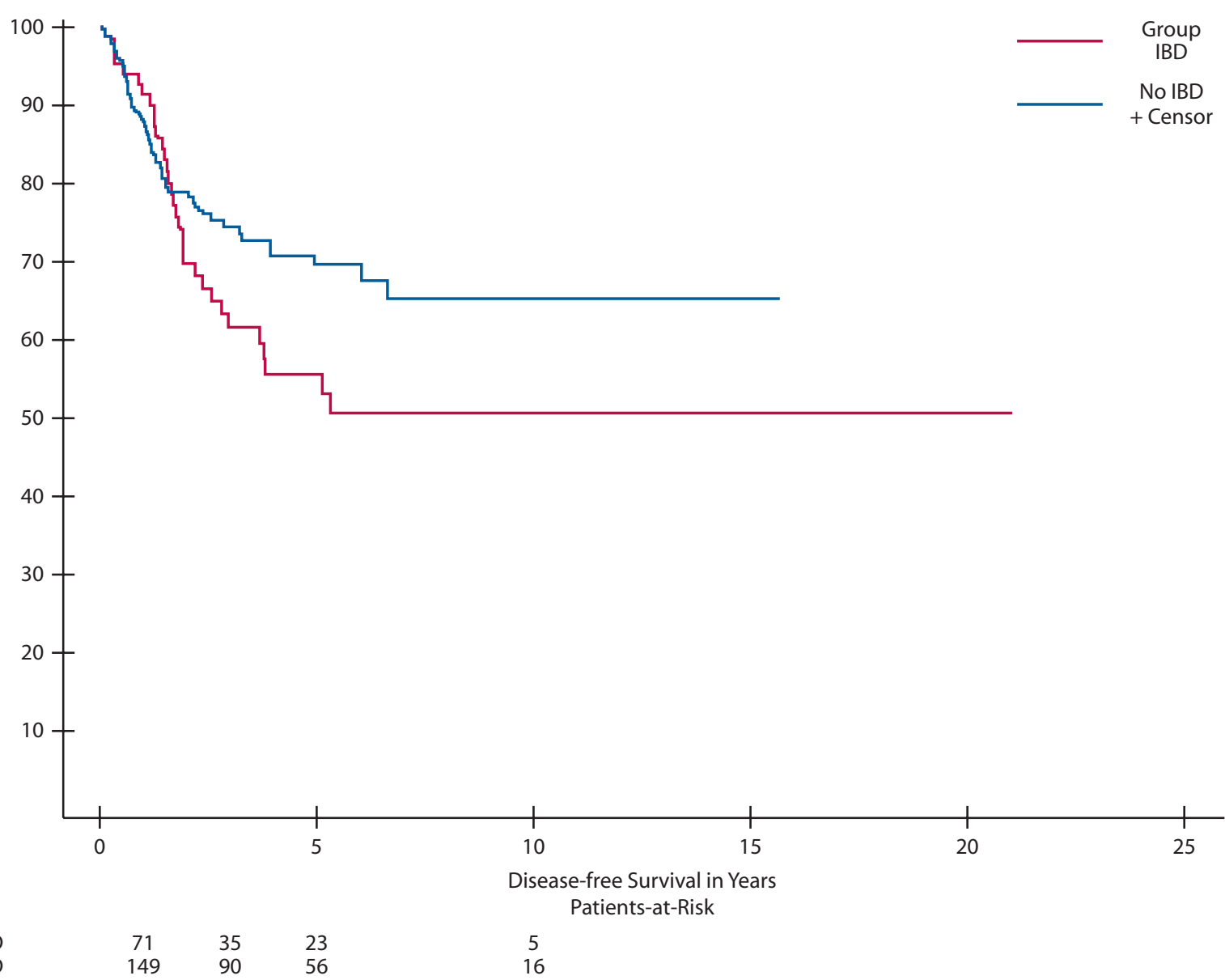

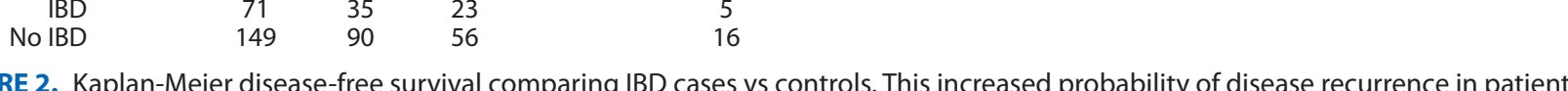
with IBD was not statistically significant (HR, 1.46; $95 \% \mathrm{Cl}, 0.94-2.28 ; p=0.092)$.

in study protocols over the past 16 years make longitudinal study challenging. Fifth, specifics on the quality of mesorectal resection (beyond assessment of CRM involvement) were lacking. However, in our institution, oncological and surgical strategies were highly standardized throughout the study period. Finally, closer follow-up in patients with CD related to disease activity may have affected follow-up and estimated survival of this subgroup.

\section{CONCLUSION}

In summary, this single-center series revealed no significant differences in overall and disease-free survival between patients with IBD and without IBD who have rectal cancer. However, patients with IBD underwent less neoadjuvant treatment and had increased rates of circumferential margin positivity. This topic should be further investigated through multicenter investigations with larger cohorts allowing for further subgroup analyses.

\section{REFERENCES}

1. Eaden JA, Abrams KR, Mayberry JF. The risk of colorectal cancer in ulcerative colitis: a meta-analysis. Gut. 2001;48:526-535.

2. Canavan C, Abrams KR, Mayberry J. Meta-analysis: colorectal and small bowel cancer risk in patients with Crohn's disease. Aliment Pharmacol Ther. 2006;23:1097-1104.

3. Ekbom A, Helmick C, Zack M, Adami HO. Ulcerative colitis and colorectal cancer. A population-based study. N Engl J Med. 1990;323:1228-1233.

4. Ekbom A, Helmick C, Zack M, Adami HO. Increased risk of large-bowel cancer in Crohn's disease with colonic involvement. Lancet. 1990;336:357-359.

5. Askling J, Dickman PW, Karlén P, et al. Family history as a risk factor for colorectal cancer in inflammatory bowel disease. Gastroenterology. 2001;120:1356-1362.

6. Soetikno RM, Lin OS, Heidenreich PA, Young HS, Blackstone MO. Increased risk of colorectal neoplasia in patients with primary sclerosing cholangitis and ulcerative colitis: a meta-analysis. Gastrointest Endosc. 2002;56:48-54.

7. Rutter MD, Saunders BP, Wilkinson KH, et al. Cancer surveillance in longstanding ulcerative colitis: endoscopic appearances help predict cancer risk. Gut. 2004;53:1813-1816. 
8. Breynaert C, Vermeire S, Rutgeerts P, Van Assche G. Dysplasia and colorectal cancer in inflammatory bowel disease: a result of inflammation or an intrinsic risk? Acta Gastroenterol Belg. 2008;71:367-372.

9. Gupta RB, Harpaz N, Itzkowitz S, et al. Histologic inflammation is a risk factor for progression to colorectal neoplasia in ulcerative colitis: a cohort study. Gastroenterology. 2007;133:1099-105.

10. Romano M, DE Francesco F, Zarantonello L, et al. From inflammation to cancer in inflammatory bowel disease: molecular perspectives. Anticancer Res. 2016;36:1447-1460.

11. Laine L, Kaltenbach T, Barkun A, McQuaid KR, Subramanian V, Soetikno R; SCENIC Guideline Development Panel. SCENIC international consensus statement on surveillance and management of dysplasia in inflammatory bowel disease. Gastrointest Endosc. 2015;81:489-501.e26.

12. Kim BJ, Yang SK, Kim JS, et al. Trends of ulcerative colitis-associated colorectal cancer in Korea: a KASID study. J Gastroenterol Hepatol. 2009;24:667-671.

13. Itzkowitz SH, Yio X. Inflammation and cancer IV. Colorectal cancer in inflammatory bowel disease: the role of inflammation. Am J Physiol Gastrointest Liver Physiol. 2004;287:G7-G17.

14. Hughes RG, Hall TJ, Block GE, Levin B, Moossa AR. The prognosis of carcinoma of the colon and rectum complicating ulcerative colitis. Surg Gynecol Obstet. 1978;146:46-48.

15. Lavery IC, Chiulli RA, Jagelman DG, Fazio VW, Weakley FL. Survival with carcinoma arising in mucosal ulcerative colitis. Ann Surg. 1982;195:508-512.

16. Ritchie JK, Hawley PR, Lennard-Jones JE. Prognosis of carcinoma in ulcerative colitis. Gut. 1981;22:752-755.

17. Ribeiro MB, Greenstein AJ, Sachar DB, et al. Colorectal adenocarcinoma in Crohn's disease. Ann Surg. 1996;223:186-193.

18. Jewel Samadder N, Valentine JF, Guthery S, et al. Colorectal cancer in inflammatory bowel diseases: a population-based study in Utah. Dig Dis Sci. 2017;62:2126-2132.

19. Shu X, Ji J, Sundquist J, Sundquist K, Hemminki K. Survival in cancer patients hospitalized for inflammatory bowel disease in Sweden. Inflamm Bowel Dis. 2011;17:816-822.

20. Ording AG, Horváth-Puhó E, Erichsen R, et al. Five-year mortality in colorectal cancer patients with ulcerative colitis or Crohn's disease: a nationwide population-based cohort study. Inflamm Bowel Dis. 2013;19:800-805.

21. Ou B, Zhao J, Guan S, Lu A. Survival of colorectal cancer in patients with or without inflammatory bowel disease: a metaanalysis. Dig Dis Sci. 2016;61:881-889.

22. Peyrin-Biroulet L, Lepage C, Jooste V, Guéant JL, Faivre J, Bouvier AM. Colorectal cancer in inflammatory bowel diseases: a population-based study (1976-2008). Inflamm Bowel Dis. 2012;18:2247-2251.
23. Sobin LH. TNM klasifikacia zhubných nádorov. Kosice: ETC Grafo; 2002.

24. Benson AB, Venook AP, Al-Hawary MM, et al. Rectal Cancer, Version 2.2018, NCCN Clinical Practice Guidelines in Oncology. J Natl Compr Canc Netw. 2018;16:874-901.

25. Bernstein CN, Blanchard JF, Kliewer E, Wajda A. Cancer risk in patients with inflammatory bowel disease: a population-based study. Cancer. 2001;91:854-862.

26. Jess T, Gamborg M, Matzen P, Munkholm P, Sørensen TI. Increased risk of intestinal cancer in Crohn's disease: a meta-analysis of population-based cohort studies. Am J Gastroenterol. 2005;100:2724-2729.

27. Gollins S, Sebag-Montefiore D. Neoadjuvant treatment strategies for locally advanced rectal cancer. Clin Oncol ( $R$ Coll $R a-$ diol). 2016;28:146-151.

28. Habr-Gama A, São Julião GP, Perez RO. Nonoperative management of rectal cancer: identifying the ideal patients. Hematol Oncol Clin North Am. 2015;29:135-151.

29. Delaunoit T, Limburg PJ, Goldberg RM, Lymp JF, Loftus EV Jr. Colorectal cancer prognosis among patients with inflammatory bowel disease. Clin Gastroenterol Hepatol. 2006;4:335-342.

30. Bansal P, Sonnenberg A. Risk factors of colorectal cancer in inflammatory bowel disease. Am J Gastroenterol. 1996;91:44-48.

31. Larsen M, Mose H, Gislum M, et al. Survival after colorectal cancer in patients with Crohn's disease: a nationwide population-based Danish follow-up study. Am J Gastroenterol. 2007;102:163-167.

32. Jensen $A B$, Larsen $M$, Gislum $M$, et al. Survival after colorectal cancer in patients with ulcerative colitis: a nationwide population-based Danish study. Am J Gastroenterol. 2006;101:1283-1287.

33. Ouaïssi M, Maggiori L, Alves A, et al. Colorectal cancer complicating inflammatory bowel disease: a comparative study of Crohn's disease vs ulcerative colitis in 34 patients. Colorectal Dis. 2011;13:684-688.

34. Smith JJ, Garcia-Aguilar J. Advances and challenges in treatment of locally advanced rectal cancer. JClin Oncol. 2015;33:1797-1808.

35. Bujko K, Nowacki MP, Nasierowska-Guttmejer A, Michalski W, Bebenek M, Kryj M. Long-term results of a randomized trial comparing preoperative short-course radiotherapy with preoperative conventionally fractionated chemoradiation for rectal cancer. Br J Surg. 2006;93:1215-1223.

36. Quirke P, Steele R, Monson J, et al; MRC CR07/NCIC-CTG CO16 Trial Investigators; NCRI Colorectal Cancer Study Group. Effect of the plane of surgery achieved on local recurrence in patients with operable rectal cancer: a prospective study using data from the MRC CR07 and NCIC-CTG CO16 randomised clinical trial. Lancet. 2009;373:821-828. 